\title{
Technical Improvements of Difficult Tracheotomy
}

\author{
Yongzhong Fan • Jundan Cai • Chaojun Yan
}

Received: 18 November 2013 / Accepted: 8 May 2014 / Published online: 30 May 2014

(C) Association of Surgeons of India 2014

\begin{abstract}
The aim of this study was to explore the application value of technical improvements of difficult tracheotomy. Percutaneous dilatational tracheotomy kit combined with traditional surgical tracheotomy was performed on seven patients with various types of difficult tracheotomy surgery from Jan. 2011 to Mar. 2013 in our hospital. The indicators, such as difficulty degree and intraoperative peripheral oxygen saturation changes of each patient, were assessed and analyzed. The average operating time was $20 \mathrm{~min}$ (from the beginning of skin incision to the implantation of the tracheal tube), and the time from cutting out tracheal cartilage rings to completely implanting tracheal tube was with $2 \mathrm{~min}$; the intraoperative oxygen saturation degrees were all above $92 \%$. There were no serious complications, such as intraoperative hemorrhea, asphyxia, cardiac arrest, or others, and no complications, such as postoperative bleeding, pneumothorax, cervical spinal cord injury, tracheal stenosis, tracheoesophageal fistula, or others, appeared. The technical improvements used in difficult tracheotomy could reduce the risk of surgery, difficulties of the surgical operation and postoperative complications and make the operation much more easy and more suitable for the clinical application.
\end{abstract}

Keywords Surgical tracheotomy · Percutaneous dilatational tracheostomy · Percutaneous dilatational tracheostomy kit . Difficult tracheotomy $\cdot$ Technological improvements

\footnotetext{
Y. Fan $(\bowtie) \cdot$ C. Yan

Department of Neurosurgery, Danyang People's Hospital,

Danyang 212300, Jiangsu Province, China

e-mail: yongzhongfan@yeah.net

J. Cai

Intensive Care Unit, Danyang People's Hospital,

Danyang 212300, Jiangsu Province, China
}

\section{Introduction}

Tracheotomy is a common surgery to rescue critically ill patients [1], a reliable artificial airway, and an essential lifesaving rescue measure toward the rescue of patients with severe airway obstruction because of various reasons. The traditional surgical tracheotomy (ST) is to tracheotomize in the operating room, very commonly used currently. In the past two decades, this technology has gradually been replaced by percutaneous dilatational tracheostomy (PDT) [2-7]. Despite the rapid evolution and improvements in technique of PDT, there continues to be apprehension in the medical community about its applicability to the high-risk patient $[8,9]$. In difficult tracheotomy, patients suffered postposture cervical spine injury, chunky neck, anatomic variations, respiratory failure requiring positive end-expiratory pressure (PEEP), and were affected by not tolerating a long time of breathing machine offline and intubation difficulties [10, 11]. The above two tracheotomies all have some kinds of incision difficulties or relative contraindications. Many domestic or foreign scholars $[9,12-14]$ have already described the causes and countermeasures of difficult tracheotomy. In this paper, we devised an advanced method for tracheal incision, the experience of the author of percutaneous dilatational tracheotomy kit (PDTk) applied into ST (hereinafter abbrev. as PDTk jointed ST) in the clinical application was introduced as the following:

\section{Subjects and Methods}

General Information

From Jan. 2011 to Mar. 2013, the ICU and NICU of our hospital (incomplete statistics) performed 275 tracheotomies; among which, PDT was 259 times, and 5 cases were difficult tracheotomy through preoperative evaluation, accounting for 
$1.82 \%$; therefore, the improved tracheotomy was then preformed. Two patients were subjected to conversion to PDTk jointed ST due to a tracheal casing pipe slip during and after PDT, respectively. Therefore, a total of seven patients received PDTk jointed ST. The detailed information about the seven patients is summarized in Table 1. This study was conducted in accordance with the declaration of Helsinki. This study was conducted with approval from the Ethics Committee of Danyang People's Hospital. Written informed consent was obtained from all participants.

Procedures

PDTk jointed ST surgical procedures: patient lied supinely on the bed; two surgeons, in cooperation with an anesthetist and a nurse, paved appropriate cushion under the shoulder to make the head hypsokinesis; and toward the patient with cervical spine fracture, orthopedic surgeon made the neck in a proper position. During the surgery, the blood pressure, heart rate, ECG, and oxygen saturation were monitored, and bipolar coagulation was performed. After disinfection, paving sterile towels and successful local anesthesia, the space between the lower edge of the thyroid cartilage and $1-\mathrm{cm}$ above the upper edge of the sternum was located, the skin and subcutaneous tissue were incised to expose the muscle along the neck midline, the muscle bundle in the midline was bluntseparated, the lamina pretrachealis was peeled and the thyroid was raised with a goiter retractor, three-four tracheal cartilage rings were exposed, and the field size diameter was about $1.0 \mathrm{~cm}$; the trachea cannula was pushed to the position of 15 $17 \mathrm{~cm}$ to fore-tooth, the " $T$ "-shaped incision was picked open with a knife, a tracheal cartilage ring was cut, and the top-"J"shaped-guide wire was placed, which would guide a tracheal dilator for the trachea expansion (this step could be omitted). Along the guide wire, a non-bacteria paraffin-lubricated 7.5\# tracheal tube was placed inside, obese patient used $8 \#$ tracheal tube; then the guide wire and the dilator were removed; after the airflow was smooth, balloon inflation was performed, the airway was closed, and the trachea cannula opening was temporarily blocked; if no significant gas leaked from the trachea incision, then muscle and skin were layeredly sutured; the tracheal tube fixed, the incision covered with sterile materials, extubated, and then the ventilator was connected.

\section{Results}

Seven cases of PDTk jointed ST operations were completed with 15-25 min (from the beginning of skin incision to the implantation of the tracheal tube); the average time was $20 \mathrm{~min}$, the time from skin incision to exposure of the trachea cartilage ring was $13-23 \mathrm{~min}$,
Table 1 The information of seven patients

\begin{tabular}{|c|c|c|c|}
\hline Patient & $\begin{array}{l}\text { Age } \\
\text { (years) } \\
\text { sex }\end{array}$ & BMI & Comorbid disease and risk factors \\
\hline 1 & $77 \mathrm{M}$ & 22.9 & $\begin{array}{l}\text { Chronic obstructive pulmonary disease } \\
\text { (COPD), suffering re-tracheotomy after 3- } \\
\text { year healing of tracheotomy and chunky } \\
\text { neck; required mechanical ventilation }\end{array}$ \\
\hline 2 & $50 \mathrm{M}$ & 22.5 & $\begin{array}{l}\text { Cervical spine fracture patients at } \mathrm{C} 2 \text { and } \mathrm{C} 3 \\
\text { requiring surgical treatment; while not yet, } \\
\text { suffered high paraplegia and required } \\
\text { mechanical ventilation }\end{array}$ \\
\hline 3 & $52 \mathrm{M}$ & 24.1 & $\begin{array}{l}\text { Cervical spine fracture patient at } \mathrm{C} 2, \mathrm{C} 3 \text {, and } \\
\mathrm{C} 4 \text {, requiring surgical treatment; while not } \\
\text { yet, suffered chunky neck and obesity; } \\
\text { required mechanical ventilation }\end{array}$ \\
\hline 4 & $24 \mathrm{M}$ & 30.4 & $\begin{array}{l}\text { Suffered severe craniocerebral trauma, and } \\
\text { percutaneous rotating tracheotomy was } \\
\text { performed, but the casing slipped with } \\
\text { hemorrhea, chunky neck, and obesity; } \\
\text { Required mechanical ventilation }\end{array}$ \\
\hline 5 & $65 \mathrm{~F}$ & 27.9 & $\begin{array}{l}\text { The patient with cardiopulmonary } \\
\text { resuscitation, appearing pseudobulbar } \\
\text { palsy; after the stopping of breathing } \\
\text { machine and pulling out the trachea } \\
\text { cannula, he suffered rapid suffocation so } \\
\text { the tube was intubated again for the } \\
\text { mechanical ventilation }\end{array}$ \\
\hline 6 & $45 \mathrm{~F}$ & 29.3 & $\begin{array}{l}\text { Suffered severe craniocerebral trauma, } \\
\text { chunky neck, and obesity }\end{array}$ \\
\hline 7 & $56 \mathrm{~F}$ & 28.0 & $\begin{array}{l}\text { Suffered aneurysmal subarachnoid } \\
\text { hemorrhage, Hunt-Hess IV grade; after } \\
\text { percutaneous rotating tracheostomy, the } \\
\text { casing slipped in the surgery, and he had the } \\
\text { problems of chunky neck and obesity }\end{array}$ \\
\hline
\end{tabular}

and the time from tracheotomy cartilage ring incision to tracheal tube placement was within $2 \mathrm{~min}$; the whole operative process was smooth, and intraoperative monitoring of oxygen saturation was more than $92 \%$. During the tracheal cartilage ring incision to the placement of tracheal tube, oxygen saturation of P1 dropped from 97 to $92 \%$, while the other six patients maintained the oxygen saturation at 95-100 \%. Intraoperative bleeding volume was $<20 \mathrm{ml}$, and no intraoperative hemorrhea, asphyxia, cardiac arrest, and other serious complications appeared; the postoperative bleeding, subcutaneous emphysema, pneumothorax, and other complications did not appear either; no tracheal stenosis, tracheoesophageal fistula, and other complications happened in the later stage. One patient eventually died of multiple organ failure. P2 and P3 showed no change in preoperative and postoperative Frankel grade. P4 was confirmed intraoperatively: innominate vein injury caused bleeding, and 8 \# tracheal tube was chosen for the obesity. 


\section{Discussion}

Difficult tracheotomy has no authoritative definition in academia yet; in the previous literature, many authors used the vocabulary "difficult tracheal intubation" $[15,16]$. Combined with the literature, the definition could be summarized as follows: difficult tracheotomy is the situation that due to anatomical abnormalities; trauma; special physical, serious diseases; and other objective reasons, a tracheotomy-trained surgeon could not complete the tracheotomy within the normal time or serious complications, including death, occurred due to a variety of operating difficulties.

In 1909, Chevalier Jackson published a report on tracheotomy indication, application, materials, methods, and standards in clinical applications, and several hospitals carried out tracheotomy. Thereafter, tracheotomy became a necessary measure to rescue critically ill patients with upper airway obstruction, throat infections, prolonged mechanical ventilation, and so on [11].

The first report of percutaneous tracheotomy was by Shelden in 1955 [17], but this technique did not become widely used until Ciaglia described the first percutaneous dilatational tracheotomy in 1985 [18]. After years of clinical application and improvement, in 2007, Paul De Leyn recommended PDT to be the choice for performing elective tracheotomy in critically ill adult patients (level 1B) [19].

In the overview and guidelines of Paul De Leyn, he discussed the safety and the surgical methods in tracheotomy of the patients with obesity, short neck, spinal cord injury, and respiratory failure of high PEEP ventilation [19]. Performing PDT in morbidly obese patients carries an increased, although acceptable, risk for perioperative complications [8, 20]. Patients with short necks might be at no higher risk during either a PDT or ST [21]. The decision whether to perform PDT or ST should depend upon the experience of the practitioner and the possibility to identify anatomical landmarks.

There were not too many reports about tracheotomy toward cervical spinal cord injury patients [22-24]. PDT is safe 610 days after anterior spine fixation particularly in the presence of spinal cord injury. In the studies reported, PDT was guided by ultrasound [22, 23].

Paul De Leyn recommended that PDT should not be performed by an inexperienced practitioner when a free airway needed to be established urgently in case of difficult intubation [19].

Tracheotomy tube slippage is also one of the complications [25-28]. There were little reports about the slippage or failed placement of tracheal tube in one time in the early stage (within a week) and in the exact tracheotomy procedure, in which case often accompanied by bleeding from wound surface, and it would be difficult to place it once again, especially fatal in the upper respiratory tract obstruction cases [25].
Pratt LW, in 2008, summarized PDT relative contraindications in the article "Tracheotomy: Historical Review": relative contraindications to perform percutaneous dilatational tracheotomy are as follows: children younger than 12 years of age, anatomic abnormality of the trachea, pulsating palpable blood vessel over the tracheotomy site, active infection over the tracheotomy site, occluding thyroid mass or goiter over the tracheotomy site, short or obese neck, positive end-expiratory pressure $15 \mathrm{~cm} \mathrm{H}_{2} \mathrm{O}$, platelet count $40,000 / \mathrm{mm}^{3}$, bleeding time $10 \mathrm{~min}$, prothrombin time or partial thromboplastin time 1.5 times control, limited ability to extend the cervical spine, and history of difficult intubation [11].

Summarizing the above reports, obesity merged stubby neck, postoperative neck surgery, tracheal tube slippage with bleeding or unclear anatomical anatomy would lead to a higher risk in surgical PDT and ST operation. After the surgery of cervical fracture, dislocation or cervical spine surgery, postural factors, local inability of burdening force, and small operating space would increase the difficulties of operation. In the tracheotomy of early tracheal tube slippage with bleeding, high PEEP ventilation patients with respiratory failure, it required fast, accurate, and safe placement of tracheal tube into the trachea, so surgery should be simple, stable, and easy to operate.

In our technology improvements, there was no need for the neck to be in hyperextended position; in the patients with cervical fracture and cervical spinal cord injury, it could maintain the cervical vertebra in the fixed position without applying pressure to different cervical directions. The operation could be performed once the 3 rd or 4 th cartilage ring was exposed, and the space diameter was about $1.0 \mathrm{~cm}$ so that a cartilage ring could be cut out. In this paper, in the two cases of cervical spine fractures, internal fixation surgery was not performed, and neck posture immobilization was performed by the orthopedic surgeon; then, there was no cervical vertebra direction pressure during the surgery operation, so it did not cause cervical displacement and further injury.

In this paper, the patient requiring PEEP for respiratory failure exhibited rapid oxygen saturation decrease because he could not endure the breathing machine offline; therefore, the operation needed to accurate and fast. Our technical improvements could make the time, from the tracheal ring cutting to the casing placement, less than $2 \mathrm{~min}$, and placement of "J"shaped guide wire was under direct vision without tension, causing no damage to the posterior wall of the trachea and no possibility of tracheal esophageal leakage. The tracheal tube was placed under the guide wire; therefore, it could be accurate and fast. "Fast" here referred to the airway cutting to casing placement time.

Obesity, short neck, and neck reoperation patient showed unclear tracheal cartilage anatomical landmarks; therefore, it would be difficult for soldering puncture in PDT technology to reach 2, 3, and 4 tracheal rings and required assisted 
positioning. The technology incised the skin, subcutaneous, and tracheal rings under direct vision and could accurately locate tracheal rings. In this case, short neck and obesity was not a separate risk factor; these patients also were accompanied with respiratory insufficiency, cervical spine fracture, and other life-threatening diseases, so the surgery needed to be fast, safe, and accurate.

Intraoperative and early tracheal tube slippage is often fatal and must maintain oxygen saturation to be more than $95 \%$; if not, emergency intubation or simple breathing bag mask must be applied for the ventilation assistance. The second time PDT could not guarantee the incision to be the original one; therefore, it could only be replaced by an open surgical incision. The guide wire slid out when the tracheal tube was guided into P7, the casing could not be loaded, and the oxygen saturation dropped from 100 to $96 \%$; then, simple breathing bag mask was given for ventilation assistance, oxygen saturation recovered to $98 \%$, and endotracheal intubation was performed; when the blood pressure, heart rate, ECG, and oxygen saturation became stable, the surgeon continued to performed the improved technology beside the bed. Although the light and hemostasis were not better than the operation room, the situation of the intensive care unit could meet the surgical conditions, so it was also convenient and reliable.

In PDT, high-risk surgery requires experienced and skilled physicians and operators [6, 19], while the improved technology was relatively simple, surgeons who could perform ST and PDT were capable of quick learning for the operation.

\section{Conclusion}

In short, the application of PDTk jointed ST could greatly reduce the risks of surgery, reduce the difficulty of surgical procedures and shorten the operation time, and reduce postoperative complications, meeting the ventilation needs of the patients with difficult tracheotomy. The operation was easy, less invasive, easy to learn and operate, and would be more suitable for clinical application. While the cases with difficult tracheotomy were fewer, they were not sufficient yet for the effective statistics. We want to use this kind of surgery for more cases and further study its indications, contraindications, and complications.

\section{Conflict of Interest None.}

Ethics Committee Letter This study was conducted in accordance with the declaration of Helsinki. This study was conducted with approval from the Ethics Committee of Danyang People's Hospital. Written informed consent was obtained from all participants.

\section{References}

1. Scurry WC Jr, McGinn JD (2007) Operative tracheotomy. Oper Tech Otolaryngol 18:85-89

2. Simpson TP, Day CJE, Jewkes CF, Manara AR (1999) The impact of percutaneous tracheostomy on intensive care unit practice and training. Anaesthesia 54:186-189

3. Walz MK (2001) Die Tracheostomie. Chirurg 72:1101-1110

4. Sharpe MD, Parnes LS, Drover JW, Harris C (2003) Translaryngeal tracheostomy: experience of 340 cases. Laryngoscope 113:530-536

5. Dulguerov P, Gysin C, Perneger TV, Chevrolet JC (1999) Percutaneous or surgical tracheostomy: a meta-analysis. Crit Care Med 27:1617-1625

6. Oreadi D, Carlson ER (2012) Morbidity and mortality associated with tracheotomy procedure in a university medical centre. Int J Oral Maxillofac Surg 41:974-977

7. Mantovani M, Rinaldi V, Torretta S, Pignataro L (2012) Tracheotomy-related morbidity and mortality: what else can we do to reduce them? Int J Oral Maxillofac Surg 41:1589-1590

8. Blankenship DR, Kulbersh BD, Gourin CG, Blanchard AR, Terris DJ (2005) High-risk tracheostomy: exploring the limits of the percutaneous tracheostomy. Laryngoscope 115:987-989

9. White HN, Sharp DB, Castellanos PF (2010) Suspension laryngoscopy-assisted percutaneous dilatational tracheostomy in high-risk patients. Laryngoscope 120:2423-2429

10. Goldenberg D, Bhatti N (2005) Management of the impaired airway in the adult. In: Cummings CW, Flint PW, Harker LA et al (eds) Cummings otolaryngology head neck surgery, 4th edn. Elsevier Mosby, Philadelphia, pp 2441-2453

11. Pratt LW, Ferlito A, Rinaldo A (2008) Tracheotomy: historical review. Laryngoscope 118:1597-1606

12. Kornblith LZ, Burlew CC, Moore EE, Haenel JB, Kashuk JL, Biffl WL, Barnett CC, Johnson JL (2011) One thousand bedside percutaneous tracheostomies in the surgical intensive care unit: time to change the gold standard. J Am Coll Surg 212:163-170

13. Grigo AS, Hall ND, Crerar-Gilbert AJ, Madden BP (2005) Rigid bronchoscopy-guided percutaneous tracheostomy. Br J Anaesth 95: 417-419

14. Mitchell RM, Eisele DW, Goldenberg D (2010) The tracheotomy punch for urgent tracheotomy. Laryngoscope 120(Suppl 4 N):198

15. Paolini JB, Donati F, Drolet P (2013) Review article: videolaryngoscopy: another tool for difficult intubation or a new paradigm in airway management? Can J Anaesth 60:184-191

16. Muallem M, Baraka A (2012) Aids for facilitation of difficult tracheal intubation review and recent advances. Middle East J Anesthesiol 21: 785-791

17. Shelden CH, Pudenz RH, Freshwater DB, Crue BL (1955) A new method for tracheotomy. J Neurosurg 12:428-431

18. Ciaglia P, Frisching R, Syniec C (1985) Elective percutaneous dilatational tracheostomy. A new simple bedside procedure: preliminary report. Chest 87:715-719

19. De Leyn P, Bedert L, Delcroix M, Depuydt P, Lauwers G, Sokolov Y, Van Meerhaeghe A, Van Schil P (2007) Tracheotomy: clinical review and guidelines. Eur J Cardiothorac Surg 32:412-421

20. Byhahn C, Lischke V, Meininger D, Halbig S, Westphal K (2005) Peri-operative complications during percutaneous tracheostomy in obese patients. Anaesthesia 60:12-15

21. Tabaee A, Geng E, Lin J, Kakoullis S, McDonald B, Rodriguez H, Chong D (2005) Impact of neck length on the safety of percutaneous and surgical tracheotomy: a prospective, randomized study. Laryngoscope 115:1685-1690

22. Sustic A, Krstulovic B, Eskinja N, Zelić M, Ledić D, Turina D (2002) Surgical tracheostomy versus percutaneous dilational tracheostomy 
in patients with anterior cervical spine fixation: preliminary report. Spine 27:1942-1945

23. O'Keeffe T, Goldman RK, Mayberry JC, Rehm CG, Hart RA (2004) Tracheostomy after anterior cervical spine fixation. J Trauma 57:855860

24. de Cerio D, Canduela P, Preciado Lopez JA, Gonzalez Barrutia VG (2011) Cervical spine fracture. Tracheotomy? Acta Otorrinolaringol Esp 62:479-480

25. Grundmann U, Schick B, Rensing H (2003) Life-threatening displacement of a tracheostomy tube in a patient with severe angiotensin-converting enzyme inhibitor-induced angioedema. Anaesthesist 52:47-50
26. Romero PC, Cornejo RR, Ruiz CM, Gálvez AR, Llanos VO, Tobar AE, Larrondo GJ, Castro OJ (2008) Fiberoptic bronchoscopy assisted percutaneous tracheostomy: report of 100 patients. Rev Med Chil 136:1113-1120

27. Barbetti JK, Nichol AD, Choate KR, Bailey MJ, Lee GA, Cooper DJ (2009) Prospective observational study of postoperative complications after percutaneous dilatational or surgical tracheostomy in critically ill patients. Crit Care Resusc 11: 244-249

28. Rajendram R, McGuire N (2006) Repositioning a displaced tracheostomy tube with an Aintree intubation catheter mounted on a fibreoptic bronchoscope. Br J Anaesth 97:576-579 